\title{
Individualised risks of stillbirth at advanced maternal age: A literature review of the evidence
}

\author{
Morgan Weathington ${ }^{A, B} R M, B S C, B M \cdot$ Jean Patterson ${ }^{C} R M, P h D \cdot$ Rae Hickey $^{C} R M, B M, P G D i p$
}

\author{
${ }^{\text {A }}$ Corresponding \\ Author: \\ morgan.e.weathington \\ @gmail.com \\ ${ }^{\text {B }}$ Self-employed LMC
} Midwife, Wanaka

C Otago Polytechnic School of Midwifery

\begin{abstract}
Introduction: Women worldwide are having their babies later than in previous generations. Advanced maternal age (AMA) has been associated with adverse pregnancy outcomes, the most severe being increased risk of stillbirth. This literature review examines the evidence for risk of stillbirth at term for women aged 40 or over in high income countries, and outlines factors found in the literature that amplify or mitigate the risk. The aim is to assist New Zealand (NZ) AMA women to make informed choices around induction of labour (IOL) which is frequently recommended at 39 weeks gestation as a general district health board (DHB) guideline for women of AMA.
\end{abstract}

Methods: Databases searched included Google Scholar, CINAHL, Science Direct, PubMed, ProQuest, and Cochrane. Seven papers met the inclusion criteria. Stillbirth risk was assessed against the exacerbating or mitigating factors within the individual papers and compared, if appropriate. Guideline documents regarding NZ obstetric recommendations for AMA were also hand searched.

Findings: The risk of stillbirth is associated with increasing maternal age beyond age 40 with the range of adjusted odds ratios (AORs) of 1.43 to 3.04. However, absolute risk of stillbirth for Australian and $\mathrm{NZ}$ women over age 40 remains very low at 4.05 stillbirths/1000 undelivered pregnancies, or an absolute risk factor above a baseline rate of 3.4/1000 for stillbirths ( $>24 \mathrm{wks}$ ). Further, the stillbirth risk for women of AMA may be modified by parity and general health.

Conclusion: AMA is associated with increasing stillbirth rates, although the absolute rate remains low and can potentially be modified by parity and general health. Therefore, women of AMA in the $\mathrm{NZ}$ context have the opportunity to assess their overall risk in consultation with their maternity carer, including these factors, when making a decision about early term IOL.

Keywords: stillbirth, advanced maternal age, induction of labour, New Zealand

\section{INTRODUCTION}

There is a growing trend in developed nations such as the United Kingdom (UK), Western European countries, Australia, Canada and New Zealand (NZ) for women to delay childbearing to later in their lives (Royal College of Obstetricians and Gynaecologists [RCOG], 2009). From 2005 to 2014 the birth rate for NZ women over 40 increased by $17 \%$, from 13 to 15.3 births/ 1000 women of reproductive age (Ministry of Health $[\mathrm{MOH}], 2015 \mathrm{a}$ ). The reasons women are making this choice are often associated with the availability of safe effective contraception, continuing education, career development, achieving financial independence, seeking a stable relationship with a supportive partner, sophisticated fertility treatments, and shifts in the female gender role (Carolan, 2003; RCOG, 2009).

In the last 100 years, the notion that "older" mothers are at higher risk in pregnancy and birth has flourished (Hallgrimsdottir \& Benner, 2014). There is a large volume of literature, although inconsistent, associating increasing risk with advancing maternal age (Carolan \& Frankowska, 2011; Flenady et al., 2011; Kenny et al., 2013). AMA pregnancies (defined in this paper as mothers $>40$ years) are associated with higher rates of hypertension and diabetes (Cleary-Goldman et al., 2005; Joseph et al., 2005), and women in general will accrue skeletal damage, cancers and other underlying medical conditions as they age (Suplee, Dawley, \& Bloch, 2007).
AMA is also associated with a range of adverse pregnancy outcomes: low birth weight, preterm birth, stillbirth and unexplained death, and increased rates of assisted births and caesarean sections (Bayrampour \& Heaman, 2010; Cleary-Goldman et al., 2005; Flenady et al., 2011; Fretts, 2005; Herstad et al., 2014; Tough et al., 2006). However, there is lack of consensus in the literature regarding at what age this risk becomes significant (Carolan \& Fankowska, 2011). Further, the underlying cause of these pregnancy outcomes, when the known pathophysiology of underlying disease is not the cause, is yet to be determined.

Currently in NZ, it is common to recommend induction of labour (IOL) at 39 weeks gestation for women of AMA beyond age 40 (Canterbury District Health Board [CDHB], 2014; Capital \& Coast District Health Board [CCDHB], 2015; Wise et al., 2014). Over $40 \%$ of women over the age of 40 are being induced (MOH, 2015b), although the reason for these inductions is unclear. A guideline of IOL for AMA after 39 weeks is seen as a way to minimise the risk of AMA and term complications, mainly stillbirth. However, the routine or blanket application of a guideline fails to account for individualised risk assessment as happens within the NZ model of midwifery partnership.

Population-based studies (national datasets), although powered to detect a rare event such as stillbirth, are consistent in reporting an association with women aged over 40 and stillbirth (1.72-3.3 OR, 
95\% CI), but have insufficient data to reveal differences in risk based on quality/quantity of antenatal care, model of care, parity, body mass index (BMI), underlying conditions, socio-economic status and education (Ananth, Liu, Kinzler, \& Kramer, 2005; Bateman \& Simpson, 2006; Fretts, 2005). When variables such as general health, socio-economic status, education and parity are controlled for, as they are in hospital-based or cohort studies, the risk of stillbirth for women of AMA is smaller (Flenady et al., 2011; Waldenstrom, Cnattingius, Norman, \& Schytt, 2015).

NZ has a unique maternity system. Community midwifery care of low-risk women is embedded into primary care and is fully funded. NZ midwifery care, whether in the hospital or the community, promotes partnership and informed choice, continuity of care, cultural safety, normal physiology if appropriate, and a welldefined referral pathway to secondary care when needed (Rowland, McLeod, \& Froese-Burns, 2012). Antenatal care is encouraged to begin before 10 weeks and is to be provided in a safe, timely, equitable and efficient manner. Continuity of care is promoted, and there is a mandatory minimum number of postnatal visits $(\mathrm{MOH}, 2007)$. Information sharing between the woman and the midwife is paramount; for instance, the NZ midwifery partnership allows for women's perception of fetal wellbeing to hold as much validity as other clinical findings and would be acted upon if necessary (Stacey et al., 2011a). In this review, the risks of stillbirth for women over 40 years of age will be considered within this NZ maternity context with reference to the changing demographics.

\section{Search strategy}

On 20th February 2015, Google Scholar, CINAHL, Science Direct, PubMed, ProQuest and Cochrane Databases were searched using the terms: "Advanced maternal age or AMA" and "Risk or Adverse outcome or stillbirth" and "New Zealand". A further search used the terms: "Advanced maternal age" and "Guidelines "and "New Zealand". Guideline documents regarding NZ obstetric recommendations for AMA were also hand searched.

Inclusion criteria were: NZ; studies involving maternal factors such as BMI, socio-economic status, education, underlying disease, midwifery care; advanced maternal age beyond 40 years old; and stillbirth rate.

Exclusion criteria were: datasets older than 20 years (due to a different demographic of high parity and lower socio-economic status), and therefore studies conducted earlier than 1996. Seven studies fitted the inclusion criteria and are summarised in Table 1.

\section{FINDINGS}

The literature reviewed included one systematic review, which examines eight studies of stillbirth and women over age 40, (Carolan \& Frankowska, 2011). In addition, three population-based studies (Ananth et al., 2005; Gordon, Raynes-Greenow, McGeechan, Morris, \& Jeffery, 2013; Waldenstrom et al., 2015) and three hospital or cohort studies were examined (Arnold, Beckmann, Flenady, \& Gibbons, 2012; Khalil, Syngelaki, Maiz, Zinevich, \& Nicolaides, 2013; Mutz-Dehbalaie et al., 2014). All studies were retrospective and observational, therefore causation of stillbirth could not be determined due to possible confounding variables, but associations could be inferred (Sedgwick, 2014). According to Sedgwick and Marston, (2010), because stillbirth is a rare event, odds ratios (OR) are a good estimate of population relative risk. ORs were compared in six of the seven papers reviewed. The Australian study (Gordon et al., 2013) was confident in the comprehensive collection of every stillbirth that happened in New South Wales over their study time period and therefore calculated a hazard risk - which is relative risk over time, in this case as gestation progresses.
AMA pregnancies in women 40 years and older were associated with increased risk of stillbirth when compared to younger women in the majority of the studies reviewed. Five of the six individual studies reviewed here also showed an association with stillbirth and age beyond 40. The ORs were: 1.66 (95\% CI 1.03-2.66) when compared to women aged 25-34 (Mutz-Dehbalaie et al., 2014); 1.88 in Norway (95\% CI 1.29-2.75) and 2.33 in Sweden (95\% CI 1.85-2.95) when compared to ages 25-29 in the same countries (Waldenstrom et al., 2015); and 2.42 (95\% CI 1.045.62) when compared to women aged 25-29 (Arnold et al., 2012). Ananth et al. (2005) also showed an association between age and stillbirth (OR 2); however, the difference, between the baseline stillbirth rates of white women (3 stillbirths/1000 livebirths) and black women (6.5 stillbirths/1000 livebirths) in this study, demonstrates that there are factors other than age that influence how often there is a stillbirth outcome. All the studies within Carolan and Frankowska's (2011) review showed an association (the range of the eight ORs 1.67-3.04) between 40 years and older and stillbirth, although the absolute rate remained low.

In Australia, Gordon et al. (2013) demonstrated an adjusted hazard ratio of 2.58 (95\% CI 1.67-4.01) for primiparous women over age 40 and 2.32 (95\% CI 1.52-3.56) for multiparous women over age 40 when compared to women aged 20-24. Whereas Khalil et al. (2013) demonstrated no difference in number of stillbirths between women over the age of 40 and women aged 3539, after accounting for variables such as method of conception, smoking, hypertension, diabetes and parity. Thus, the absolute risk of stillbirth in high income countries remains very low, about 3.1 stillbirths/1000 livebirths (Cousens et al., 2011) and stillbirth continues to be a rare event in NZ (Perinatal and Maternal Mortality Review Committee [PMMRC], 2015). This rarity means that studies on our small NZ population did not meet the inclusion criteria as they were underpowered to detect differences in maternal age and stillbirth (Stacey et al., 2011b).

Findings in the research varied on aspects of general health, parity, socio-economic status, conception methods, BMI, smoking status, place of birth and model of care, and definitions of stillbirth and AMA (see Table 2). The studies that accounted for multiple variables found that education and socio-economic status influenced the stillbirth risk (Mutz-Dehbalaie et al., 2014; Waldenstrom et al., 2015). Only one paper identified midwifery care and place of birth within its dataset (Gordon et al., 2013) but these variables were not separated out as confounding variables.

Currently, NZ IOL policies for AMA are based on non-NZ studies, and do not take into account our unique maternity system. Six articles were identified that inform some of the NZ IOL policies relating to AMA. Canterbury District Health Board (CDHB) Induction of Labour Guidelines (CDHB, 2014, p. 13) are informed by Ananth et al. (2005), Bateman and Simpson, (2006) (which was within the Carolan and Frankowska (2011) review), and RCOG (2009), an opinion piece. The Capital \& Coast DHB Induction of Labour Policy for Wellington Hospital (CCDHB, 2015, p.2) is informed by Raymond, Cnattingius, and Kiely (1994), whose work was not part of the review due to the age of the dataset. An Induction of Labour Best Practice Guideline, developed by the DHBs of Auckland: Auckland, Counties Manukau, and Waitemata (Wise et al., 2014) is informed by Carolan and Frankowska (2011), RCOG (2013) (opinion) and Arnold et al. (2012). Although these studies may be generalisable to the populations of high-income nations and the changing demographic within, none of the countries in these studies has the same model of maternity care as NZ. 
Table 1. Articles reviewed for AMA and stillbirth

Authors, year, Study design Results

country

Carolan \& Systematic review of adverse outcomes for women aged Summary: rates of stillbirth associated with maternal age. Increasing rates Frankowska, $\quad 35-39.40$ and above also addressed. Review of 9 studies from 35 years on, but gaining momentum beyond age 40 . Impact of (2011) totalling 40 million women. 6: USA, 1: Canada, 1: UK, 1: changing demographics not understood.

Multiple countries Australia

Khalil et al., Hospital dataset.

The range of Odds Ratios of stillbirth for women >40: 1.67-3.04

(2013) Retrospective study. Singleton pregnancy with first AN

United Kingdom care between 11-13.6 weeks. Age is a continuous and categorical variable. 76,158 women. Association was measured as a continuous and categorical variable.

Odds Ratio of stillbirth

$35-39$ y 1.32 (95\% Cl 1.01-1.72)

$40 y$ or older $1.43(95 \% \mathrm{Cl} 0.90-2.27)$

These two categories are not significantly different $\mathrm{P}=0.068$.

No significant increase in stillbirth between age categories of $35-39$ and 40 or older.

Gordon et al., Population-based cohort study.

Hazard ratio calculated

(2013) State maternity/perinatal death data collections, 2002-

Absolute risk calculated: per 1000 undelivered pregnancies

Australia 2006. 327,690 births.

(Data sets = NSW Midwives Data Collection [included public/private hospitals, homebirths]; Perinatal Death Data from the NSW Perinatal \& Maternal Committee)

$\begin{array}{lcc} & \text { Nulliparous women } & \text { Multiparous women } \\ \mathbf{2 0 y} & 0.79 & 0.83 \\ \mathbf{2 0 - 2 4 y} & 0.76 & 1.07 \\ \mathbf{2 5 - 2 9 y} & 1.11 & 0.99 \\ \mathbf{3 0 - 3 4 y} & 0.87 & 0.95 \\ \mathbf{3 5 - 3 9 y} & 1.42 & 0.38 \\ \mathbf{3 0 y} & 4.05 & 1.42\end{array}$

$\begin{array}{ll}\text { Waldenstrom et } & \text { Population-based register. } \\ \text { al., (2015) } & \text { Women }>25 \text { years, singleton pregnancies, 1990-2011. }\end{array}$

Multiple countries

Odds Ratio for stillbirth, 25-29y reference

\begin{tabular}{|c|c|c|c|c|}
\hline & & & \multicolumn{2}{|l|}{ education } \\
\hline & & 1 st birth $40 y$ or older & $1.50(1.05-2.15)$ & $2.29(1.69-3.12)$ \\
\hline & & 2nd birth & $1.72(1.22-2.42)$ & $1.00(0.66-1.49)$ \\
\hline & & 3rd birth & $2.03(1.44-2.85)$ & $1.19(0.64-2.20)$ \\
\hline & & 4th birth & $1.44(1.02-2.05)$ & $1.93(0.55-6.74)$ \\
\hline Mutz-Dehbalaie & Hospital dataset. & \multicolumn{3}{|l|}{ Odds Ratio for stillbirth } \\
\hline et al., (2014) & Retrospective cohort study. 56,517 singleton hospital & \multicolumn{3}{|c|}{ Age 35-39: 1.03 (95\% Cl: 0.77-1.39) } \\
\hline Austria & births, 1999-2008. & \multicolumn{3}{|c|}{ Age $>401.66(95 \% \mathrm{Cl}: 1.03-2.66)$} \\
\hline & & \multicolumn{3}{|c|}{ Neonatal mortality not significantly different between groups. } \\
\hline & & \multicolumn{3}{|c|}{ Obesity \& poor antenatal are (<4 visits) amplified stillbirth outcomes. } \\
\hline Arnold, & Hospital dataset. & \multirow{6}{*}{\multicolumn{3}{|c|}{$\begin{array}{l}\text { Adjusted Odds Ratio for stillbirth } \\
\text { Age }>402.42 \text { (95\% Cl: 1.04-5.62) compared women age <35. } \\
\text { SGA fetus also independently associated with term stillbirth. }\end{array}$}} \\
\hline Beckmann, & Retrospective cohort study. Singleton births, 1998-2008, & & & \\
\hline Flenady, \& & that occurred after 37 weeks. & & & \\
\hline Gibbons, (2012) & Population: 62,351 after exclusions, & & & \\
\hline Australia & aged <40: 60,203 births, 67 stillbirths; & & & \\
\hline & aged >40: 2148 births, 6 stillbirths & & & \\
\hline Ananth, Liu, & Population-based cohort study. & \multirow{4}{*}{\multicolumn{3}{|c|}{$\begin{array}{l}\text { Overall decrease in all age cohort stillbirths over time. Relative increase of } \\
\text { stillbirths in women beyond age } 35 \text {. } \\
\text { AOR } 2.2 \text { for white women aged } 40-45 \text { compared to women aged } 25-29 \\
\text { (stillbirth rate of } 3 \text { stillbirths/ } 1000 \text { live births). }\end{array}$}} \\
\hline Kinzler, \& Kramer, & Retrospective sample of $71,037,685$ singleton live births & & & \\
\hline (2005) & and stillbirths, 1981-2000. & & & \\
\hline USA & & & & \\
\hline & & \multirow{2}{*}{\multicolumn{3}{|c|}{$\begin{array}{l}\text { AOR } 1.9 \text { for black women aged } 40-45 \text { compared to women aged } 25-29 \\
\text { (stillbirth rate of } 6.5 \text { stillbirths/ } 1000 \text { live births). }\end{array}$}} \\
\hline & & & & \\
\hline & & \multicolumn{3}{|c|}{ Odds ratio for stillbirth among black women vs. white women was 2.4 (95\% } \\
\hline & & \multicolumn{3}{|l|}{ Cl: 2.1-2.7). } \\
\hline
\end{tabular}


Table 2. Comparison of variables within papers that met the inclusion criteria

\begin{tabular}{|c|c|c|c|c|c|c|c|c|c|c|c|}
\hline \multirow{2}{*}{$\begin{array}{l}\text { Authors, year, } \\
\text { country }\end{array}$} & \multirow{2}{*}{$\begin{array}{l}\text { AMA } \\
\text { def'n }\end{array}$} & \multirow{2}{*}{$\begin{array}{l}\text { Compared } \\
\text { with age }\end{array}$} & \multirow{2}{*}{$\begin{array}{l}\text { Stillbirth } \\
\text { def'n }\end{array}$} & \multirow{2}{*}{$\begin{array}{l}\text { Exclusion of } \\
\text { aneuploidy } \\
\text { /multiples }\end{array}$} & \multicolumn{7}{|c|}{ Adjusted for } \\
\hline & & & & & $\begin{array}{l}\text { Underlying } \\
\text { disease }\end{array}$ & ART & $\begin{array}{l}\text { Type/ } \\
\text { amount } \\
\text { of care }\end{array}$ & Smoking & Parity & $\begin{array}{c}\text { Socio- } \\
\text { economic } \\
\text { status/ } \\
\text { education }\end{array}$ & BMI \\
\hline $\begin{array}{l}\text { Carolan \& } \\
\text { Frankowska, } \\
\text { (2011) }\end{array}$ & $\geq=40$ & $\begin{array}{l}\text { Systematic } \\
\text { review }\end{array}$ & & & & & & & & & \\
\hline $\begin{array}{l}\text { Khalil et al., } \\
\text { (2013) }\end{array}$ & $\geq=40$ & $35-39$ & $>24 \mathrm{wks}$ & yes & yes & yes & no & yes & Null only & no & no \\
\hline UK & & & & & & & & & & & \\
\hline $\begin{array}{l}\text { Gordon et al., } \\
\text { (2013) Australia }\end{array}$ & $>40$ & $\begin{array}{c}\text { Absolute risk } \\
\text { calc. }\end{array}$ & $\begin{array}{l}>22 \mathrm{wks} \\
\text { or }>400 \mathrm{~g} \\
\text { before } \\
\text { labour }\end{array}$ & yes & yes & yes & yes & yes & Null \& Multi & no & no \\
\hline $\begin{array}{l}\text { Waldenstrom et } \\
\text { al., (2015) }\end{array}$ & $>40$ & $25-29$ & $>22 \mathrm{wks}$ & no & yes & no & no & yes & Null \& Multi & yes & yes \\
\hline $\begin{array}{l}\text { Mutz-Dehbalaie } \\
\text { et al., (2014) }\end{array}$ & $>40$ & & $>500 \mathrm{~g}$ & no & yes & no & yes & yes & $\begin{array}{l}\text { Identified } \\
\text { but not }\end{array}$ & yes & yes \\
\hline Austria & & & & & & & & & compared & & \\
\hline $\begin{array}{l}\text { Arnold, } \\
\text { Beckmann, }\end{array}$ & $>40$ & $<35$ & $>37 w k s$ & yes & yes & yes & no & yes & no & no & yes \\
\hline $\begin{array}{l}\text { Flenady, \& } \\
\text { Gibbons, (2012) } \\
\text { Australia }\end{array}$ & & & & & & & & & & & \\
\hline $\begin{array}{l}\text { Ananth, Liu, } \\
\text { Kinzler, \& } \\
\text { Kramer, (2005) } \\
\text { USA }\end{array}$ & $40-45$ & $25-29$ & $>20 w k s$ & no & no & no & yes & no & no & no & no \\
\hline
\end{tabular}

Note the differences in definitions of stillbirth and AMA which will affect reported stillbirth rates.

\section{DISCUSSION}

Comparing stillbirth rates between studies has been difficult. The studies are set in different countries, the women included differ in parity, and definitions of stillbirth and AMA are varied. Other factors, such as pregnancies following assisted reproduction technology (ART), issues around BMI, variations in socio-economic status, education, general health and lifestyle, and antenatal care, may or may not be considered (see Table 2). There are no NZ AMA stillbirth rates with which to compare the international rates; as previously noted, Stacey et al., (2011b) is not powered to detect differences in maternal age and stillbirth risk, therefore is not included in this review.

Carolan and Frankowska's (2011) review, involving more than 40 million women, clearly linked increased rates of stillbirth to women beyond age 40; however, the degree of association varied considerably between the studies, from OR 1.62 (Canterino, Ananth, Smulian, Harrigan, \& Vintzileos, 2004) to OR 3.04 (Bahtiyar et al., 2006). Improved socio-economic status and education and a reduction of the risk of stillbirth was marginally supported (Cleary-Goldman et al., 2005; O'Leary, Bower, Knuiman, \& Stanley, 2007; Yuan et al., 2000) although not well understood.

Individualised care is the hallmark of NZ midwifery and is underpinned by facilitating women's ability to make an informed choice (Guilliland \& Pairman, 2010); therefore, knowing and sharing which factors can influence a woman's risk for stillbirth are important. However, rates of stillbirth for AMA women within the studies reviewed are difficult to apply to the individual NZ woman; this is due to the heterogeneity of study cohorts and definitions between the studies (Suplee et al., 2007). For example, two of the six individual studies differentiated stillbirth results between parities (Gordon et al., 2013; Waldenstrom et al., 2015) and showed that multiparity can be protective against stillbirth at advanced maternal age. BMI was accounted for in only three of the six studies (Arnold et al., 2012; Mutz-Dehbalaie et al., 2014; Waldenstrom et al., 2015), despite high BMI complicating care and increasing risk of stillbirth (Flenady et al., 2011). ART versus spontaneous conception was addressed in only one of the six studies (Khalil et al., 2013), despite ART being more common in older women and appearing to increase the risk of stillbirth (Bewley, Ledger, \& Nikolaou, 2009). Furthermore, definitions of when fetal death is designated a stillbirth ranged from $>20$ weeks gestation (Ananth et al., 2005) to $>37$ weeks (Arnold et al., 2012) and only one study differentiated between antepartum and intrapartum stillbirth (Gordon et al., 2013). These differences in studies make comparison and application of rates difficult.

It is accepted that the risk for stillbirth increases as a woman ages (Khalil et al., 2013); however, the cohort of 40 years and over does not account for the differences between a 40 -year-old pregnant woman and a pregnant 50-year-old-it is assumed the stillbirth risk is the same. Only Ananth et al. (2005) had categories for ages 40-44 and 45-49, showing an increase in risk with age. It could 
be assumed that women closer to 40 would have a lower risk of stillbirth to that of women closer to 50 .

\section{Factors exacerbating or mitigating risk}

Waldenstrom et al. (2014) recently compared the risk of fetal death $(0.21 \%)$ (measured as adjusted absolute risk) for low-risk women (non-smokers, normal weight, ages 25-29) to that of women older than 30 or who smoked or were overweight or obese. Findings showed the risk of fetal death was highest for overweight and obese women $(0.53 \%)$. Women over 40 had a risk of $0.49 \%$, compared to women aged $35-39$ whose risk was $0.37 \%$, and smoking was associated with a risk of fetal death rates of $0.33 \%$. The authors concluded that maternal age was an independent risk factor but their study did not allow for definitive conclusions about causality. Nonetheless, Flenady et al. (2011) conclude that the combination of age, increased BMI and maternal smoking increased negative outcomes substantially.

Just as some lifestyle choices may compound the effects of aging, other lifestyle choices may offset the development of pregnancyrelated problems associated with aging, as suggested by Carolan and Frankowska (2011). This theory has been backed by Suplee et al. (2007). Further, Viau, Padula, and Eddy (2002) demonstrated that women over 35 were "proactive health seekers" (p.330), changing their health behaviour patterns based on the physiological needs of their pregnancy. Women having their first baby over 40 are more likely to be of higher socio-economic status than younger women (Carolan \& Frankowska, 2011; Joseph et al., 2005)allowing these women to afford healthy food choices and time to seek out alternative health modalities to improve and maintain their health. For example, Carolan (2003) found that women of AMA may view pregnancy as a their "last chance" to become a mother and make health decisions that protect it, and higher socio-economic status and lower parity are known predictors of greater pregnancy investment and more favourable pregnancy outcomes (Viau et al., 2002). A recent study (Goetzinger, Shanks, Odibo, Macones, \& Cahill, 2014) reports that AMA women have fewer fetal anomalies, excluding aneuploidy, than their younger counterparts, and attributes this partly to healthy behaviours by women of AMA. Therefore, the large studies that do not control for socio-economic status may not be accurately reflecting the protective effect of good health and lifestyles.

As mentioned above, parity too may have an effect. Gordon et al. (2013) found that multiparity decreased the stillbirth risk in women over age 40, and Waldenstrom et al. (2015) discussed the protective effect of parity in higher socio-economic cohorts. Therefore, guidelines in NZ suggesting IOL to reduce risk of stillbirth for AMA alone, and not differentiating risk on the basis of the woman's age, parity, BMI and smoking respectively and collectively, may be overstating the benefits of IOL for preventing stillbirth.

Just as women have physiological variations in how they age, women will have had different environmental and lifestyle influences over the years. Further complicating this are the many unproven theories about the underlying pathophysiological mechanism for the increased adverse outcomes. Some of these mechanisms will be explored below, although they may be only one aspect of the adverse outcomes being reported.

\section{Pathophysiology underlying risk associated with AMA}

There are co-morbidities that often accompany pre-existing medical conditions, such as hypertension, obesity and diabetes
(Cleary-Goldman et al., 2005; Joseph et al., 2005). These underlying illnesses affect a larger percentage of older mothers (a quarter of women 45 years or older will have a chronic medical disease; Department of Health, 2004), but there are clear causeand-effect care pathways for these, and they will not be addressed here. Pathophysiological theories for the association of stillbirth with AMA, separate from these pre-existing conditions, are mainly focused on uterine aging.

In the broader literature, the pathophysiology underlying increased stillbirths, assisted deliveries and caesarean sections is mainly linked to impaired decidua development and placentation. Sclerotic lesions increase with age, which may be one factor that causes under-perfusion of the fetus, eventually leading to stillbirth (Prefumo et al., 2004). Doppler studies show more notches and higher vascular resistance in nulliparous women (Hafner, Schuchter, Metzenbauer, \& Philipp, 2000; Prefumo et al., 2004) compared to multiparous women. One hypothesis suggests that a successful first pregnancy may inherently change the uterine lining to have increased non-muscular tissue in the uterine arteries (Khong, Adema, \& Erwich, 2003) and improve the endovascular trophoblast invasion (Prefumo, Ganapathy, Thilaganathan, \& Sebire, 2006). This supports the research findings that increased parity reduces the risk of stillbirth in women of AMA (Gordon et al., 2013; Waldenstrom et al., 2015).

\section{Managing the increased risk of stillbirth in AMA women in NZ}

Primary maternity caregivers in NZ have well-defined referral guidelines $(\mathrm{MOH}, 2012)$ to determine what pre-existing or developing conditions warrant a consultation or transfer of care to the obstetric team. However, there is not a specific pathway for AMA. For conditions outlined in the referral guidelines, a threeway conversation is mandated with the woman, her lead maternity carer (LMC, a midwife in $84 \%$ of NZ cases; $\mathrm{MOH}, 2015 \mathrm{c}$ ) and the consultant. It is also possible that in a strong midwifery partnership, where the well-informed woman evaluates her own risk, she may or may not choose to consult.

Many DHB guidelines for IOL state that women of AMA, without any other risk factors, can be offered an IOL between 39 and 41 weeks (CDHB, 2014; CCDHB, 2015; Wise et al., 2014). Assessing a woman on age alone assumes that the underlying pathophysiology is universal and needs to be treated. However, the mechanism for the risk of stillbirth in women of AMA is undetermined (RCOG, 2009, 2013), as previously shown, and so treating an associated risk with a general recommendation of induction will have a large number of women being treated for few babies being saved.

Further, the iatrogenic consequences of induction are well documented; such as, lower maternal satisfaction (Brown \& Furber, 2015), increased need for epidurals (Brown \& Furber, 2015) leading to increased assisted births (McCarthy \& Kenny, 2011), and increased Neonatal Intensive Care Unit (NICU) admissions (Stock et al., 2012). Randomised controlled trials (RCTs) comparing rates of caesarean deliveries between women with IOL and those with expectant management have generally concluded that the caesarean rate is unchanged or lower with IOL (Hannah et al., 1992; Mishanina et al., 2014). However, observational studies say otherwise (Allen, O'Connell, Farrell, \& Baskett, 2005; Vahratian, Zhang, Troendle, Sciscione, \& Hoffman, 2005) and so there remains a possibility that failed IOLs possibly result in increased caesarean section rates (McCarthy \& Kenny, 2011; Shetty, Burt, Rice, \& Templeton, 2005). This 
information should be conveyed as part of the informed consent to the intervention process.

RCOG (2009) suggests that if all women aged 40 or more in the UK, with a singleton pregnancy, were induced at 39 weeks instead of 41 weeks, 17 stillbirths would have been prevented from 20092010. This would have required an extra 9350 inductions over that time period, or 550 inductions to prevent one stillbirth. To provide perspective, the number of postdates inductions needed to prevent one stillbirth after 42 weeks gestation is 410 (Gülmezoglu, Crowther, Middleton, \& Heatley, 2012). Arnold et al. (2012) calculated from their dataset that IOL at 40 weeks for women aged 40 or more, results in an extra five caesarean sections for every 100 women induced. Hypothetically, if this was the same rate for the RCOG (2009) commentary, this would mean an extra 468 caesareans for that time period, or 28 caesareans to prevent one stillbirth.

Utilising IOL to mitigate a possible maternal age risk, without any other indication, further burdens hospital secondary care resources such as staffing numbers, length of stay in unit, medicines and equipment (Druzin \& El-Sayed, 2006). IOL, assisted delivery and caesarean section all have a much higher economic cost than vaginal birth (Allen et al., 2005). Alternatively, expectant management, although it too has a cost in extra monitoring (Goeree, Hannah, $\&$ Hewson, 1995), is another way to address the possible increased risk posed by AMA.

Expectant management has been studied by Fox et al. (2013). This United States (US) retrospective cohort study (4,469 women) found that women over 35 years old did not have a higher rate of stillbirth when compared with women less than age 35 with expectant management, within an obstetric model. Women over age 35 had weekly biophysical profile testing after 36 weeks gestation, and planned delivery at 41 weeks or sooner if indicated.

However, in the greater literature the effectiveness of fetal surveillance of AMA women remains unclear and stillbirths of AMA women are often unexplained (Gordon et al., 2013; Salihu et al., 2008; Silver, 2007). A Cochrane Review (Alfirevic, Stampalija, \& Gyte, 2010) did not find any evidence that routine assessment of fetal growth or umbilical/uterine artery Dopplers could identify fetal growth restriction and therefore a higher risk for stillbirth. Similarly, Alfirevic, Stampalija and Medley (2015) could not find any benefit in using fetal Dopplers as a screening tool to identify fetal problems in low-risk babies, although they were useful to identify the at-risk fetus in known potentially high-risk cases. Although adverse outcomes such as Small for Gestational Age (SGA) and stillbirths could be caused by placental insufficiency, in women of AMA stillbirth is not associated with oligohydramnios or meconium stained amniotic fluid (Miller, 2005).

Expectant management in NZ is not solely related to external surveillance, however; it also includes close attention paid to maternal perception of fetal movements. Tveit et al. (2009) outline how information sharing about decreased fetal movements halved the stillbirth rate of the Norwegian population. A small NZ study (Peat, Stacey, Cronin, \& McCowan, 2012) indicated that, although $97 \%$ of women in NZ are being asked about fetal movements by their midwife, only half of women in midwifery care are receiving optimal information about fetal movements, which is easily incorporated into care and may influence late-term stillbirth rates.

In the NZ context, some women over 40 may not choose IOL after 39 weeks as recommended by DHB guidelines. The well-informed pregnant woman, acquainted with her risk and the gaps in what we know, may choose to be monitored for any heightened risk rather than accept a general population recommendation. Selfemployed, midwifery-led care does not have differing stillbirth rates from hospital midwifery, GP/shared or private obstetricianled care in NZ (Stacey et al., 2012), suggesting that how AMA women are being cared for within the NZ midwifery model is effective in addressing the increased risk. Therefore, individualised care within the NZ midwifery partnership model may reduce the rate of inductions for AMA alone, without increasing the stillbirth rate for this cohort of women.

Given that the rates of stillbirth do not vary between model of care or choice of LMC, more research would be helpful in uncovering if and how care of AMA women differs between models. Additionally, calculating the economic and social costs of an elective earlyterm IOL, versus expectant management within the primary care model, would be useful for the NZ maternity system. Uncovering this model could reduce the economic and social burden of more women and babies requiring secondary care, and promote choice for AMA women at the end of their pregnancies.

\section{CONCLUSION}

Midwives are increasingly caring for women over 40 years of age (Statistics New Zealand, 2014) and, while there is a large body of literature on the pregnancy and intrapartum risks of later childbearing, it is difficult to apply it to the individual woman of AMA within the NZ maternity system. This is due to lack of consensus on the underlying physiology of aging, heterogeneity of the cohorts studied within research, such as parity, socio-economic status, ART versus spontaneous conception, BMI, general health, smoking status, place of birth, model of care and caregivers' tolerance for risk for this cohort (Carolan, 2013).

Actual risk of stillbirth remains low, despite the increased association. DHB guidelines within NZ recommend IOL at 39 to 41 weeks gestation for women of AMA in order to minimise the increased stillbirth risk (CDHB, 2014; CCDHB, 2015; Wise et al., 2014). However, the population-based IOL recommendation has its own risks that may outweigh the individual risk of stillbirth (Allen et al., 2005; RCOG, 2009).

Not all AMA women in NZ are being induced at 39-40 weeks, so it seems the stillbirth risk may be addressed by expectant management. The stillbirth rates for the women cared for by self-employed midwives do not differ from those cared for by hospital midwifery teams, GP/shared or private obstetrician-led care in NZ (Stacey et al., 2012). This suggests that midwives, in collaboration with obstetricians if needed, are addressing the increased stillbirth risk for AMA effectively. More research needs to be done to investigate how AMA women are being cared for by $\mathrm{NZ}$ midwives in the community, as this model has the potential to reduce pressure on secondary care facilities and provide AMA women with more choice at the end of their pregnancies.

\section{ACKNOWLEDGEMENTS AND CONFLICT OF INTEREST STATEMENT}

This review was inspired by the women I have cared for, who are undertaking motherhood later in life. Thank you.

The authors report no conflict of interest.

\section{REFERENCES}

Alfirevic, Z., Stampalija, T., \& Gyte, G. M. (2010). Fetal and umbilical Doppler ultrasound in normal pregnancy. Cochrane Database of Systematic Reviews, (8). CD001450. http://dx.doi. org/10.1002/14651858.CD001450.pub3 
Alfirevic, Z., Stampalija, T., \& Medley N. (2015). Fetal and umbilical Doppler ultrasound in normal pregnancy. Cochrane Database of Systematic Reviews, (4). CD001450. http://dx.doi. org/10.1002/14651858.CD001450.pub4

Allen, V., O'Connell, C., Farrell, S., \& Baskett, T. (2005). Economic implications of method of delivery. American Journal of Obstetrics and Gynecology, 193(1), 192-197.

Ananth, C., Liu, S., Kinzler, W., \& Kramer, M. (2005). Stillbirths in the United States, 1981-2000: An age, period, and cohort analysis. American Journal of Public Health, 95(12), 2213-2217.

Arnold, A., Beckmann, M., Flenady, V., \& Gibbons, K. (2012). Term stillbirth in older women. Australian and New Zealand Journal of Obstetrics \& Gynaecology, 52, 286-289.

Bahtiyar, M., Funai, E., Norwitz, E., Buhimschi, C., Rosenberg, V., \& Copel, J. (2006). Advanced maternal age (AMA) is an independent predictor of intrauterine fetal death at term. American Journal of Obstetrics and Gynecology, 195(6), 209.

Bateman, B., \& Simpson, L. (2006). Higher rates of stillbirth at the extremes of reproductive age: A large nationwide sample of deliveries in the United States. American Journal of Obstetrics and Gynecology, 194(3), 840-845.

Bayrampour, H., \& Heaman, M. (2010). Advanced maternal age and the risk of caesarean birth: a systematic review. Birth, 37(3), 219-226. http://dx.doi.org/10.1111/j.1523-536X.2010.00409.x.

Bewley, S., Ledger, W., \& Nikolaou, D. (Eds). (2009). Reproductive ageing. London, UK: RCOG Press.

Brown, S. J. \& Furber, C. M. (2015). Women's experiences of cervical ripening as inpatients on an antenatal ward. Sexual \& Reproductive Healthcare, 6(4), 219-225. http://dx.doi.org/10.1016/j. srhc.2015.06.003

Canterbury District Health Board (CDHB). (2014). Induction of Labour Guidelines. Retrieved from: http://www.cdhb.health.nz/HospitalsServices/Health-Professionals/maternity-care-guidelines/Documents/ GLM0035-Induction-of-Labour.pdf

Canterino, J., Ananth, C. V., Smulian, J., Harrigan, J. T., \& Vintzileos, A. M. (2004). Maternal age and risk of fetal death in singleton gestations: USA, 1995-2000. Journal of Maternal-Fetal and Neonatal Medicine, 15, 193-197.

Capital \& Coast District Health Board (CCDHB). (2015). Induction of labour guidelines. New Zealand: Capital \& Coast District Health Board.

Carolan, M. (2003). The graying of the obstetric population: Implications for the older mother. Journal of Obstetric, Gynecologic, \& Neonatal Nursing, 32, 19-27.

Carolan, M. (2013). Maternal age $>/=45$ years and maternal and perinatal outcomes: A review of the evidence. Midwifery, 29, 479-489.

Carolan, M., \& Frankowska, D. (2011). Advanced maternal age and adverse perinatal outcome: A review of the evidence. Midwifery, 27, 793-801.

Cleary-Goldman, J., Malone, F., Vidaver, J., Ball, R., Nyberg, D., Comstock, C...D'Alton, M. (2005). Impact of maternal age on obstetric outcome. Obstetrics \& Gynecology, 105(5 Pt 1), 983-990.

Cousens, S., Blencowe, H., Stanton, C., Chou, D., Ahmed, S., Steinhardt, L...Lawn, J. (2011). National, regional, and worldwide estimates of stillbirth rates in 2009 with trends since 1995: a systematic analysis. Lancet, 377, 1319-1330. Retrieved from: https://www. researchgate.net/profile/Hannah_Blencowe/publication/51054888_ National_regional_and_worldwide_estimates_of_stillbirth_ rates_in_2009_with_trends_since_1995_A_systemic_analysis/ links/00b4952c1804969acf000000.pdf

Department of Health (2004). Health Survey for England 2003. London, UK: Department of Health. Retrieved from http://www.dh.gov.uk/asset/ Root/04/09.89/11/04098911.pdf.

Druzin, M., \& El-Sayed, Y. (2006). Cesarean delivery on maternal request: wise use of finite resources? A view from the trenches. Seminars in Perinatology, 30(5), 305-308.

Flenady, V., Koopmans, L., Middleton, P., Frøen, J. F., Smith, G. C., Gibbons, K...Ezzati, M. (2011). Major risk factors for stillbirth in high-income countries: a systematic review and meta-analysis. Lancet, $377,1331-1340$
Fox, N., Rebarber, A., Silverstein, M., Roman, A., Klauser, C., \& Saltzman, D. (2013). The effectiveness of antepartum surveillance in reducing the risk of stillbirth in patients with advanced maternal age. European Journal of Obstetrics \& Gynecology and Reproductive Biology, $170(2), 387-390$

Fretts, R. C. (2005). Etiology and prevention of stillbirth. American Journal of Obstetrics and Gynecology, 193(6), 1923-1935.

Goeree, R., Hannah, M., \& Hewson, S. (1995). Cost-effectiveness of induction of labour versus serial antenatal monitoring in the Canadian Multicentre Post-term Pregnancy Trial. Canadian Medical Association Journal, 152(9), 1445-1450.

Goetzinger, K. R., Shanks, A., Odibo, A., Macones, G., \& Cahill, A. (2014). Advanced maternal age and the risk of major congenital anomalies: survival of the fittest? American Journal of Obstetrics and Gynecology, 210(1), S23.

Gordon, A., Raynes-Greenow, C., McGeechan, K., Morris, J., \& Jeffery, H. (2013). Risk factors for antepartum stillbirth and the influence of maternal age in New South Wales Australia: A population based study. BMC Pregnancy and Childbirth, 13, 12

Guilliland, K., \& Pairman, S. (2010). The Midwifery Partnership. A Model for Practice (2nd ed.). Christchurch, NZ: New Zealand College of Midwives.

Gülmezoglu, A., Crowther, C., Middleton, P., \& Heatley, E. (2012). Induction of labour for improving birth outcomes for women at or beyond term. Cochrane Database of Systematic Reviews (6). CD004945. http://dx.doi.org/10.1002/14651858.CD004945.pub3

Hafner, E., Schuchter, K., Metzenbauer, M., \& Philipp, K. (2000). Uterine artery Doppler perfusion in the first and second pregnancies. Ultrasound in Obstetrics \& Gynecology, 16(7), 625-629. http://dx.doi. org/10.1046/j.1469-0705.2000.00290.x

Hallgrimsdottir, H., \& Benner, B. (2014). 'Knowledge is power': risk and the moral responsibilities of the expectant mother at the turn of the twentieth century. Health, Risk \& Society, 16(1).

Hannah, M. E., Hannah, W. J., Hellmann, J., Hewson, S., Milner, R., \& Willan, A. (1992). Induction of labour as compared with serial antenatal monitoring in post-term pregnancy. A randomized controlled trial. The Canadian Multicenter Post-term Pregnancy Trial Group. New England Journal of Medicine, 326, 1587-1592.

Herstad, L., Klungsøyr, K., Skjærven. R., Tanbo. T., Forsén, L., Åbyholm, T., \& Vangen, S. (2014). Maternal age and emergency operative deliveries at term: a population-based registry study among low-risk primiparous women. BJOG: An International Journal of Obstetrics and Gynaecology, Published online Aug 6, 2014. http://dx.doi.org/10.1111/1471-0528.12962

Joseph, K. S., Allen, A. C., Dodds, L., Turner, L. A., Scott, H., \& Liston, R. (2005). The perinatal effects of delayed childbearing. Obstetrics and Gynecology, 105(6), 1410-1418.

Kenny, L., Lavender, T., McNamee, R., O’Neill, S., Mills, T., $\&$ Khashan, A. (2013). Advanced maternal age and adverse pregnancy outcome: Evidence from a large contemporary cohort. PLOS ONE, 8(2), e56583. http://dx.doi.org/10.1371/journal. pone. 0056583

Khalil, A., Syngelaki, A., Maiz, N., Zinevich, Y., \& Nicolaides, K. H. (2013). Maternal age and adverse pregnancy outcome: a cohort study. Ultrasound in Obstetrics \& Gynecology, 42, 634-643.

Khong, T. Y., Adema, E. D., \& Erwich, J. J. (2003). On an anatomical basis for the increase in birth weight in second and subsequent born children. Placenta, 24(4), 348-353.

McCarthy, F., \& Kenny, L. (2011). Induction of labour. Obstetrics, Gynaecology and Reproductive Medicine, 21(1), 1-6.

Miller, D. A. (2005). Is advanced maternal age an independent risk factor for uteroplacental insufficiency? American Journal of Obstetrics and Gynecology, 192(6), 1974-1980.

Ministry of Health (MOH). (2007). Section 88. Primary maternity services notice 2007. Wellington, NZ: Ministry of Health. Retrieved from: http://www.health.govt.nz/publication/section-88-primarymaternity-services-notice-2007

Ministry of Health (MOH). (2012). Guidelines for Consultation with Obstetric and Related Medical Services (Referral Guidelines). Wellington, NZ: Ministry of Health. Retrieved from: http://www.health.govt.nz/ system/files/documents/publications/referral-glines-jan12.pdf 
Ministry of Health (MOH). (2015a). Report on Maternity, 2014. Wellington, NZ: Ministry of Health. Retrieved from: http://www.health. govt.nz/system/files/documents/publications/report-on-maternity-2014dec15.pdf

Ministry of Health (MOH). (2015b). Maternity Tables 2013. Wellington, NZ: Ministry of Health. Retrieved from: http://www.health.govt.nz/ publication/maternity-tables-2013

Ministry of Health (MOH). (2015c). Maternity Consumer Survey 2014. Wellington, NZ: Research New Zealand. Retrieved from https://www. health.govt.nz/publication/maternity-consumer-survey-2014

Mishanina, E., Rogozinska, E., Thatthi, T., Uddin-Khan, R., Khan, K., \& Meads, C. (2014). Use of labour induction and risk of cesarean delivery: a systematic review and meta-analysis. Canadian Medical Association Journal, 186(9), 665-673.

Mutz-Dehbalaie, I., Scheier, M., Jerabek-Klestil, S., Brantner, C., Windbichler, G., Leitner, H... Oberaigner, W. (2014). Perinatal Mortality and Advanced Maternal Age. Gynecologic and Obstetric Investigation, 77, 50-57.

O'Leary, C. M., Bower, C., Knuiman, M., \& Stanley, F. J. (2007). Changing risks of stillbirth and neonatal mortality associated with maternal age in Western Australia 1984-2003. Paediatric and Perinatal Epidemiology, 21, 541-549.

Peat, A., Stacey, T., Cronin, R., \& McCowan, L. (2012). Maternal knowledge of fetal movements in late pregnancy. Australian and New Zealand Journal of Obstetrics and Gynaecology, 52(5), 445-449. http:// dx.doi.org/10.1111/j.1479-828x.2012.01462.x

Perinatal and Maternal Mortality Review Committee (PMMRC). (2015). Ninth annual report of the perinatal and maternal mortality review committee: Reporting mortality 2013. Wellington, NZ: Health Quality \& Safety Commission New Zealand. Retrieved from: http://www.hqsc. govt.nz/assets/PMMRC/Publications/Ninth-PMMRC-report-FINALJun-2015.pdf

Prefumo, F., Bhide, A., Sairam, S., Penna, L., Hollis, B., \&

Thilaganathan, B. (2004), Effect of parity on second-trimester uterine artery Doppler flow velocity and waveforms. Ultrasound in Obstetrics \& Gynecology, 23, 46-49. http://dx.doi.org/10.1002/uog.908

Prefumo, F., Ganapathy, R., Thilaganathan, B., \& Sebire, N. J. (2006). Influence of parity on first trimester endovascular trophoblast invasion. Fertility and Sterility, 85(4), 1032-1036.

Raymond, E. G., Cnattingius, S., \& Kiely, J. L. (1994). Effects of maternal age, parity, and smoking on the risk of stillbirth. BJOG: An International Journal of Obstetrics \& Gynaecology, 101, 301-306. http:// dx.doi.org/10.1111/j.1471-0528.1994.tb13614.x

Rowland, T., McLeod, D., \& Froese-Burns, N. (2012). Malatest

International - comparative study of maternity systems. Report prepared for the Ministry of Health, NZ. Retrieved from: http://www.health.govt. $\mathrm{nz} /$ system/files/documents/publications/comparative-study-of-maternitysystems-nov13.pdf

Royal College of Obstetricians and Gynaecologists (RCOG). (2009).

RCOG statement on later maternal age. Retrieved from: https://www.rcog. org.uk/en/news/rcog-statement-on-later-maternal-age/

Royal College of Obstetricians and Gynaecologists (RCOG). (2013). Induction of labour at term in older mothers. Scientific Impact Paper, No. 34. Retrieved from: https://www.rcog.org.uk/globalassets/documents/ guidelines/scientific-impact-papers/sip_34.pdf

Salihu, H. M., Sharma, P. P., Getahun, D., Hedayatzadeh, M., Peters, S., Kirby, R. S...Gaafer-Ahmed, H. (2008). Prenatal tobacco use and risk of stillbirth: A case-control and bidirectional case-crossover study. Nicotine \& Tobacco Research, 10(1), 159-166.

Sedgwick, P. (2014). Retrospective cohort studies: advantages and disadvantages. British Medical Journal, 348, g1072.

Sedgwick, P., \& Marston, L. (2010). Odds ratios. British Medical Journal, 341, c4414.

Shetty, A., Burt, R., Rice, P., \& Templeton, A. (2005). Women's perceptions, expectations and satisfaction with induced labour - A questionnaire-based study. European Journal of Obstetrics \& Gynecology \& Reproductive Biology, 123(1), 56-61.

Silver, R. M. (2007). Fetal death. Obstetrics \& Gynecology, 109, 153-167.

Stacey, T., Thompson, J., Mitchell, E., Ekeroma, A., Zuccollo, J., \& McCowan, L. (2011a). Maternal perception of fetal activity and late stillbirth risk: Findings from the Auckland Stillbirth Study. Birth, 38(4), 311-316.
Stacey, T., Thompson, J., Mitchell, E., Ekeroma, A., Zuccollo, J., \& McCowan, L. (2011b). The Auckland Stillbirth Study, a case-control study exploring modifiable risk factors for third trimester stillbirth: methods and rationale. Australian and New Zealand Journal of Obstetrics and Gynaecology, 51, 3-8.

Stacey, T., Thompson, J., Mitchell, E., Zuccollo, J., Ekeroma, A., \& McCowan, L. (2012). Antenatal care, identification of suboptimal fetal growth and risk of late stillbirth: Findings from the Auckland Stillbirth Study. Australian and New Zealand Journal of Obstetrics and Gynaecology, 52, 242-247.

Statistics New Zealand. (2014). Birth tables: Median and average age of mother. Retrieved from: http://www.stats.govt.nz/browse_for_stats/ population/births/births-tables.aspx

Stock, S., Ferguson, E., Duffy, A., Ford, I., Chalmers, J., \& Norman, J. (2012). Outcomes of elective induction of labour compared with expectant management: population based study. British Medical Journal, 344, e2838.

Suplee, P. D., Dawley, K., \& Bloch, J. R. (2007). Tailoring peripartum nursing care for women of advanced maternal age. Journal of Obstetric, Gynecologic \& Neonatal Nursing, 36(6), 616-623.

Tough, S., Benzies, K., Newburn-Cook, C., Tofflemire, K., Fraser-Lee, N., Faber, A., \& Sauve, R. (2006). What do women know about the risks of delayed childbearing? Canadian Journal of Public Health, 97(4), 330-334.

Tveit, J. V. H., Saastad, E., Stray-Pedersen, B., Bordahl, P., Flenady, V., Fretts, R., \& Froen, J. F. (2009). Reduction of late stillbirth with the introduction of fetal movement information and guidelines - a clinical quality improvement. [Erratum appears in BMC Pregnancy Childbirth. 2010, 1, 49]. BMC Pregnancy Childbirth, 9, 32.

Vahratian, A., Zhang, J., Troendle, J. F., Sciscione, A. C., \& Hoffman, M. K. (2005). Labor progression and risk of cesarean delivery in electively induced nulliparas. Obstetrics \& Gynecology, 105(4), 698-704.

Viau, P. A., Padula, C., \& Eddy, B. (2002). An exploration of health concerns \& health promotion behaviors in pregnant women over age 35 . The American Journal of Maternal/Child Nursing, 27, 328-334.

Waldenstrom, U., Aasheim, V., Nilsen, A., Rasmussen, S., Pettersson, H., \& Schytt, E. (2014). Adverse pregnancy outcomes related to advanced maternal age compared with smoking and being overweight. Obstetrics \& Gynecology, 123(1), 104-112.

Waldenstrom, U., Cnattingius, S., Norman, M., \& Schytt, E. (2015). Advanced maternal age and stillbirth risk in nulliparous and parous women. Obstetrics \& Gynecology, 126(2), 355-362.

Wise, M., Ansell, L., Belgrave, S., Farmer, E., McDougall, J., Wadsworth, S., \& Wotton, J. (2014). Auckland consensus guideline on induction of labour. Retrieved from: http://nationalwomenshealth. adhb.govt.nz/Portals/0/Documents/Referral\%20forms/FINAL $\% 20$ Auckland\%20IOL\%20consensus\%20guideline.pdf

Yuan, W., Steffensen, F. H., Nielsen, G. L., Moller, M., Olsen, J., \& Sorensen, H. T. (2000). A population-based cohort study of birth and neonatal outcome in older primipara. International Journal of Gynecology \& Obstetrics, 68, 113-118.

\section{Accepted for publication March 2017}

Weathington, M., Patterson, J., \& Hickey, R. Individualised risks of stillbirth at advanced maternal age: A literature review of the evidence (2016). New Zealand College of Midwives Journal, 53, 15-22.

http://doi.org/10.12784/nzcomjnl53.2017.2.15-22 